\title{
THE INFLUENCE OF SURFACTANT AND PROTECTIVE COLLOID ON POLYVINYL ACETATE EMULSION SYNTHESIZED BY EMULSION POLYMERIZATION TECHNIQUE
}

\author{
Adam Jaya $^{1}$, M. A. Elita Hafizah ${ }^{1}$, A. Manaf ${ }^{1, *}$, Andreas $^{2}$ \\ ${ }^{1}$ Postgraduate Program of Materials Science, Faculty of Mathematics and Natural Science, Universitas \\ Indonesia, Jl. Salemba Raya No.4, Jakarta 10430, Indonesia \\ ${ }^{2}$ Indonesian Institute of Sciences, LIPI, Komplek PUSPITEK, Serpong, Banten 15314, Indonesia \\ *Corresponding Author Email: azwar@ui.ac.id
}

Received: 27 July 2020

Revised: 31 August 2020

Accepted: 22 October 2020

Online: 27 November 2020

Published: 31 December 2020

SPEKTRA: Jurnal Fisika dan Aplikasinya

p-ISSN: 2541-3384

e-ISSN: 2541-3392

\begin{abstract}
A series of experiments have been carried out and reported. This report describes the stages of the polymerization reaction during emulsion Polyvinyl Acetate (PVAc) synthesis. PVAc was synthesized from the Vinyl Acetate Monomer (VAM) with Ammonium Peroxydisulphate (APS) as an inorganic thermal initiator in the aqueous media under reaction temperature was keep at 65 until $75^{\circ} \mathrm{Cs}$ by agitation speed was $300 \mathrm{rpm}$ respectively during 4 hours of reaction time. The protective colloid agents and several types of surfactants were added to improve the obtained emulsion PVAc performance. The polymerization reaction was carried out without the addition of a protective colloid agent. The surfactants were produced the emulsion PVAc with the properties of solid content $0.89 \%$, density $1.02 \mathrm{~g} / \mathrm{ml}$, viscosity 0.0033 Poise, $\mathrm{pH} 2.8$, conductivity $12 \mathrm{~ms}$, respectively. While the polymerization reaction involved protective colloid agents by using Polyvinyl Alcohol (PVOH) was obtained properties of emulsion PVAc with Solid Content 4.36\%, density 1.17

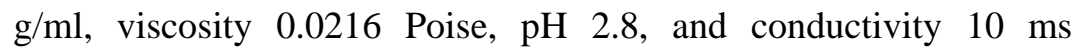
respectively. The same thing was shown when the surfactant was present in the polymerization reaction. The emulsion PVAc was synthesized with nonionic surfactant has solid content $8.20 \%$, density $1.17 \mathrm{~g} / \mathrm{ml}$, viscosity 0.0099 Poise, $\mathrm{pH} 2.8$, and conductivity $7 \mathrm{~ms}$, the result is better rather than synthesized with anionic surfactant has solid content $2.65 \%$, density $1.13 \mathrm{~g} / \mathrm{ml}$, viscosity 0.0068 Poise, $\mathrm{pH} 2.8$, and conductivity $11 \mathrm{~ms}$. According to the preliminary observations obtained, emulsion PVAc's appearance is better when the protective
\end{abstract}


colloid agents and the surfactant is present rather than without additional those substances. The physical properties of emulsion were depended on the addition of protective colloid agents and surfactants. In addition, the complete reaction indicated by solid content value was obtained from emulsion when the additional substances were present. All the testing parameters were observed using Viscometer Ostwald, Pycnometer, pH Meter, FTIR Spectrophotometer, Conductometer, and another supporting testing to explain the polymerization reaction stage of synthesis emulsion PVAc.

Keywords: emulsion polymerization, polyvinyl acetate, polyvinyl alcohol, anionic surfactant, protective colloid agent

\section{INTRODUCTION}

The development of advanced material types in the world is quite influencing the development and progress of the adhesive industry without exception and impacting the development of the adhesive industry in Indonesia [1]. Several types of adhesives that are known are distinguished by their constituent components, such as water-based, solvent-based, and hot melt adhesive [2]. Water-based adhesive is one of the adhesives developed because of low cost, easy to produce, and environmentally friendly product [3]. One type of water-based adhesive which widely used is Polyvinyl acetate (PVAc) based is known as white glue is used in several types of industries such as electrical, electronic, woodworking, paper, and medicine [4], where is the PVAc is used found in emulsion form [5].

Emulsion polymerization is one technique to synthesize emulsion of Polyvinyl acetate (PVAc). These conventional emulsion polymerizations are still an interesting technique to be developed by using hydrophobic monomer assisted with an inorganic initiator and assisted small amount of surfactants to obtain various emulsion polymerization products [6]. PVAc is one of the adhesives known due to its versatility and ease to use. This compound was made by reaction of monomers vinyl acetate by a thermal initiator such as ammonium persulfate (APS). Polyvinyl acetate is built by the polymerization reaction of Vinyl acetate monomer (VAM), which linked any others until formed to be large macromolecules [7]. Other kinds of additives as a minor component such as a surfactant, protective colloid, buffer, $\mathrm{pH}$ adjuster, foaming agents sometimes is required to obtain a better quality of PVAc emulsion [8]. This study would describe there the various effect of surfactants and colloids added to the synthesis process aimed to make the PVAc product better and the process safer.

\section{EXPERIMENT}

\subsection{Material}

A series of materials used in this research have high purity include Vinyl Acetate Monomer (VAM), Polyvinyl Alcohol (PVA), Sodium Lauryl Sulfate (SLS), Nonyl Phenol with 10-mole ethoxylate (10 EO), Ammonium Persulphate (APS). All the chemical agents were used pro 
analytical (pa) grade with purity above 99\%. The main component of solvent was used Deionized Water (DW), which resistivity of $18 \pm 0.2 \mathrm{MX}-\mathrm{cm}$.

\subsection{Synthesize of Polyvinyl Acetate}

The first stage is the solution preparation. It was prepared $30 \%$ of single component VAM for $1 \mathrm{~kg}$ of the total capacity polymerization reactor. Also, $0.2 \%$ of APS solution was prepared in DW at room temperature until dissolved completely, 3\% of SLS solution, NP 10 solution, and PVA solution for each, the composition of a solution refers to TABLE 1.

The first experiment (Code A) using 30\% of VAM was reacted with $0.2 \%$ of APS solution at $27^{\circ} \mathrm{C}$ for 4 hours of reaction time and $300 \mathrm{RPM}$ of reaction speed. The second and third experiments were reacted between $30 \%$ of VAM with $0.2 \%$ of APS solution and $3 \%$ of SLS solution, NP 10 solution, and PVA solution, respectively (Code B, Code C, and Code D). All the reaction conditions referring to the first experiment. Characterization of the obtained emulsion by solid content determination, viscosity testing, $\mathrm{pH}$ value, density, conductivity value, and chemical function group by FTIR spectrophotometer

TABLE 1. The reagent composition on the synthesis process.

\begin{tabular}{|c|c|c|c|c|}
\hline \multirow{2}{*}{ Component } & Code A & Code B & Code C & Code D \\
\hline & \multicolumn{4}{|c|}{ Composition $(\%)$} \\
\hline Vinyl Acetate Monomer (VAM) & 30 & 30 & 30 & 30 \\
\hline Ammonium Persulfate (PSA) & 0.2 & 0.2 & 0.2 & 0.2 \\
\hline Surfactant Nonionic / SLS & & 3 & & \\
\hline Surfactant Anionic / NP-10 & & & 3 & \\
\hline Polyvinyl Alcohol (PVA) & & & & 3 \\
\hline Aquades & 69.8 & 66.8 & 66.8 & 66.8 \\
\hline
\end{tabular}

\section{RESULTS AND DISCUSSION}

The synthesize of polyvinyl acetate emulsion was conducted in a glass reactor with a three necks bottle connected to the condenser. The reaction condition was carried out at $65-75^{\circ} \mathrm{C}$, with an agitation speed was $300 \mathrm{rpm}$ during 4 hours of reaction time. These system reactions were applied by the latest study of the reaction between VAM and APS [9]. The reaction may run in a closed system to avoid the decomposition of APS at higher temperatures [10]. Additional surfactant to bridge the hydrophobic phase from monomer and hydrophilic phase from the water as the major component medium by decreasing the surface tension and breaking the hydrogen bond hence through micelle formation from surfactant could build a backbone for formed polymer [11].

In the previous report, the effect of the surfactants has been described, but the usage of this kind of method isn't much known due to PVAc was done as a complementary compound for another composite or copolymer reactions. Unless using a surfactant, the development of this method by using PVA was carried out where is PVA was used as a protective colloid to avoid hydrolysis of the polyvinyl acetate since, at the higher temperature $\left(>70^{\circ} \mathrm{C}\right)$, the PVAc would be decomposed. It's been a little bit contrary because the formation process is needed 
approximately $65-75^{\circ} \mathrm{C}$. Hence the protective agent is required to produce a stable emulsion of PVAc [12].

In order to control and monitor the reaction during the polymerization process, several characterizations are required. Solid formation during polymerization could indicate polymer formation. FIGURE 1 described the solid content of the obtained polymer for all experiments. It is shown that the value of solid content is different. Code A had the lowest solid content because the reaction only depends on the monomer and initiator; hence with the same reaction time cause the conversion of the monomer is small. Besides that, the obtained polymer is unstable due to the differentiation phase of the monomer in an aqueous medium. Meanwhile, Code B, C, and D figure out the higher formation of solid content since on the third experimental there is the addition of surfactant and protective colloid to bridge the different polarity between the hydrophobic monomer and aqueous medium; hence it increased the nucleation process to produce dispersed emulsion polymer indicating by solid content [13]. The addition of either surfactant or protective colloid can produce different disperse patterns when the emulsion process occurred. The dissolved surfactant will form a micelle after the Critical Micelle Concentration (CMC) is reached, causing the surface tension of solution decreased then the polymer molecules are formed [14]. Code B and C were carried out using two different surfactant types is an anionic and nonionic surfactant. Sodium Lauryl Sulphate (SLS) as an anionic surfactant contains anion of the sulfate group, which can convert the monomer higher to be a polymer molecule [15].

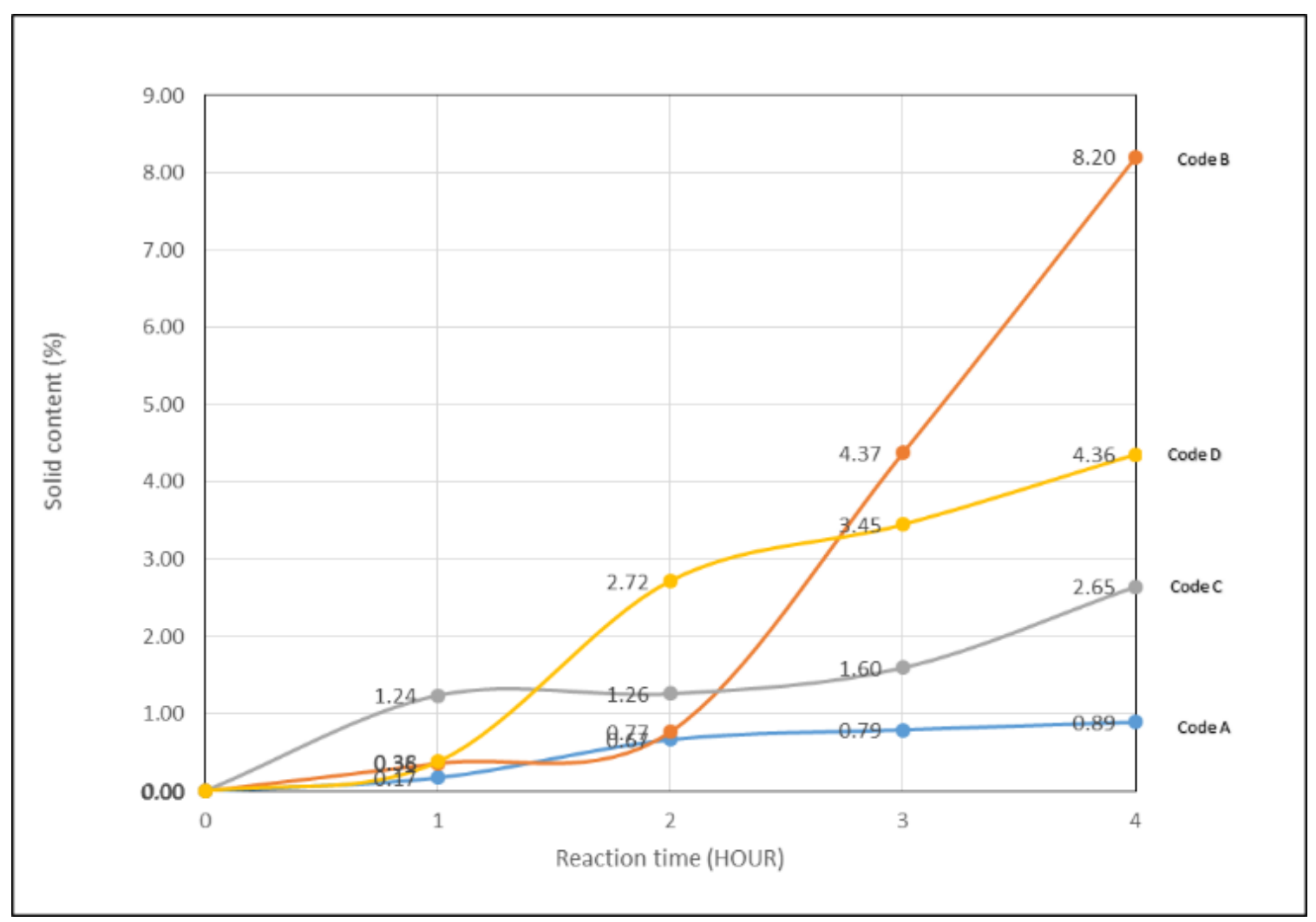

FIGURE 1. Solid Content of Polyvinyl Acetate (PVAc) Emulsion with the Presence and Absence of Surfactant/Protective Colloid 
Some publications have reported that some parameters are required as an indicator of reaction polymerization, including an increasing reaction temperature [16]. Ammonium persulphate (APS) as a thermal inorganic initiator is able to decompose at $65-75^{\circ} \mathrm{C}$. To obtain a complete decomposition of the APS reaction, the temperature is set up approximately as mentioned temperature. During the reaction is carried out monitoring of temperature changing and found an increase in temperature as described in TABLE 2. The increasing temperature is faster for Code A when the absence of surfactant and protective colloid. These caused the radical was decomposed from APS can attack directly into monomer molecules in aqueous media without any obstruction from other molecules. On the other hand, when the presence of surfactant and protective colloid, there is competition between the molecule of monomer and molecule of surfactant; hence the reaction a bit longer to reach the maximum temperature [17]. Code $\mathrm{B}, \mathrm{C}$, and $\mathrm{D}$ need almost 30 minutes to detect the highest temperature of the reaction.

TABLE 2. Temperature Reaction of Polyvinyl Acetate (PVAc) Emulsion Synthesize with Presence and Absence of Surfactant/Protective Colloid

\begin{tabular}{lll}
\hline Sample Code & Max Temperature $\left({ }^{\circ} \mathrm{C}\right)$ & Reaction Time (Hours) \\
\hline Code A & 70 & 4 \\
Code B & 72 & 4 \\
Code C & 71 & 4 \\
Code D & 71 & 4 \\
\hline
\end{tabular}

To find out, the polymerization reaction can also be determined by the increased viscosity of the solution. These indicate that the formation of macromolecules which have longer carbon chains are formed. In accordance with the existing theory where the longer of the molecular chain of a polymer compound will have higher viscosity [18]. FIGURE 2 shown the viscosity value of the formed PVAc emulsion. When surfactant and protective colloid is absent, lower viscosity is obtained. It has a correlation with solid content formed for the same experiment. At the same time, the presence of both surfactant and protective colloid will produce higher viscosity of PVAc emulsion. The increase of viscosity due to of the difference of dispersion process between the monomer and water as the medium, sample with code A, have lowest value than others because none of the presence of an agent which helped the dispersion process. The added surfactants are tougher in the dispersion and stabilization process due to hands-on when the particle's latex grows and formed. The reason is similarly same when the PVA is added, but they're a side effect because PVA contains a set of hydroxyl groups toward a hydrogen bond chain, which has an effect on the thicknesses of the solution [19].

VAM has a unique chemical group when characterized using FTIR Spectrophotometer. FIGURE 3 described the monomer conversion from VAM. VAM contains several specific fingers point due to of vibration of the $\mathrm{C}=\mathrm{O}$ strain at $1731 \mathrm{~cm}^{-1}$ and the vibration of the $\mathrm{C}-\mathrm{H}$ at $1371 \mathrm{~cm}^{-1}$. When all monomers converted to Polymer form, the characteristics of the PVAc spectrum appears specifically at $3310-3444 \mathrm{~cm}^{-1}$ indicating the $\mathrm{O}-\mathrm{H}$ chemical group function as a hydrogen bond. Then the peak showing the $\mathrm{C}-\mathrm{H}$ sp3 stretch vibration appears at $2935 \mathrm{~cm}^{-1}$, which shows the C-H sp3 stretch vibration. Meanwhile, at $1756 \mathrm{~cm}^{-1}$, there is a 
stretching vibration $\mathrm{C}=\mathrm{O}$ ester group that experiences greater wave number shift due to the effect of a vinyl long chain, at $1370 \mathrm{~cm}^{-1}$ shows vibrational buckling $\mathrm{C}-\mathrm{H}$, and at 1207-1018 $\mathrm{cm}^{-1}$ shows CO stretch vibration respectively [20].

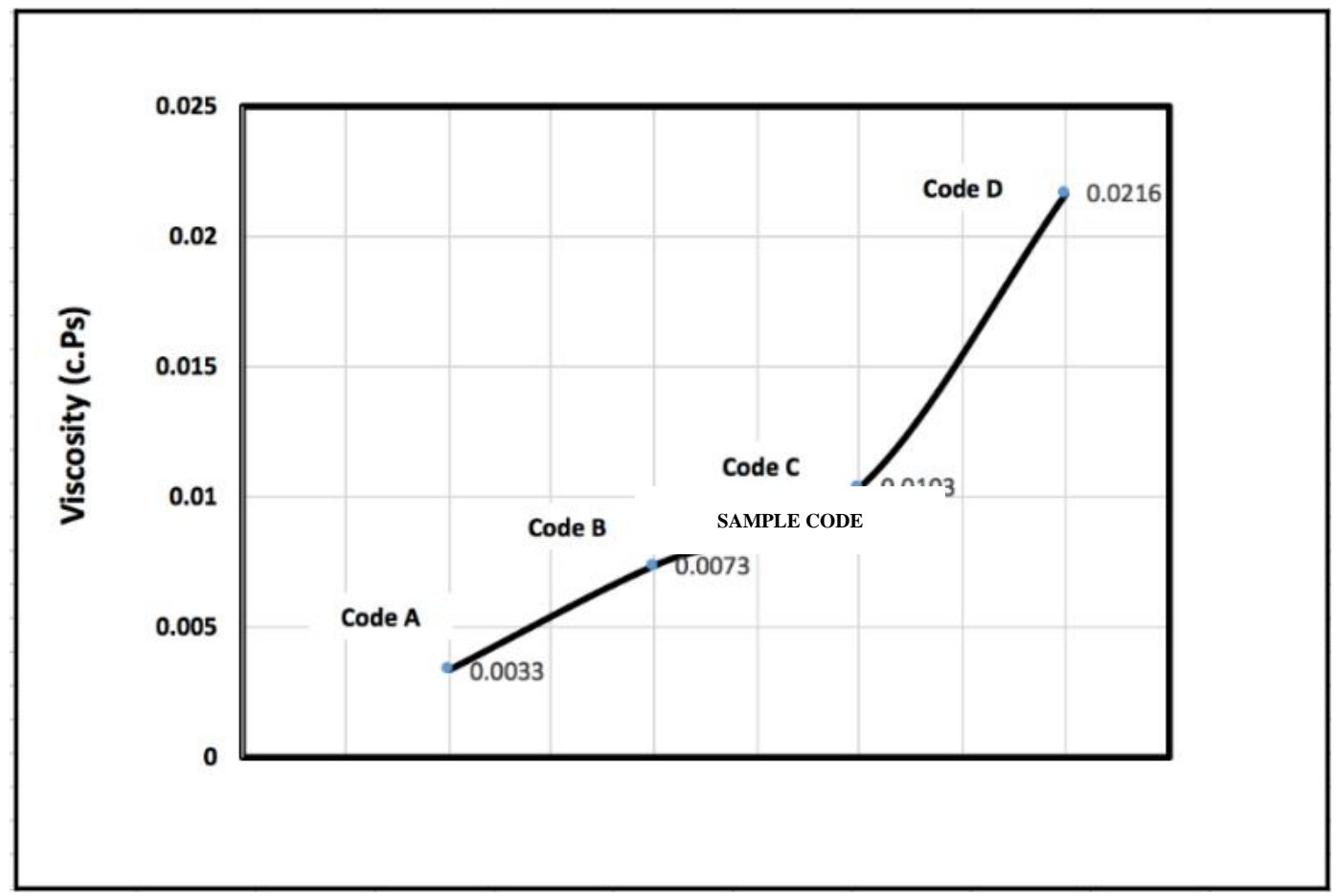

FIGURE 2. Viscosity of Polyvinyl Acetate (PVAc) Emulsion with Presence and Absence of Surfactant/Protective Colloid

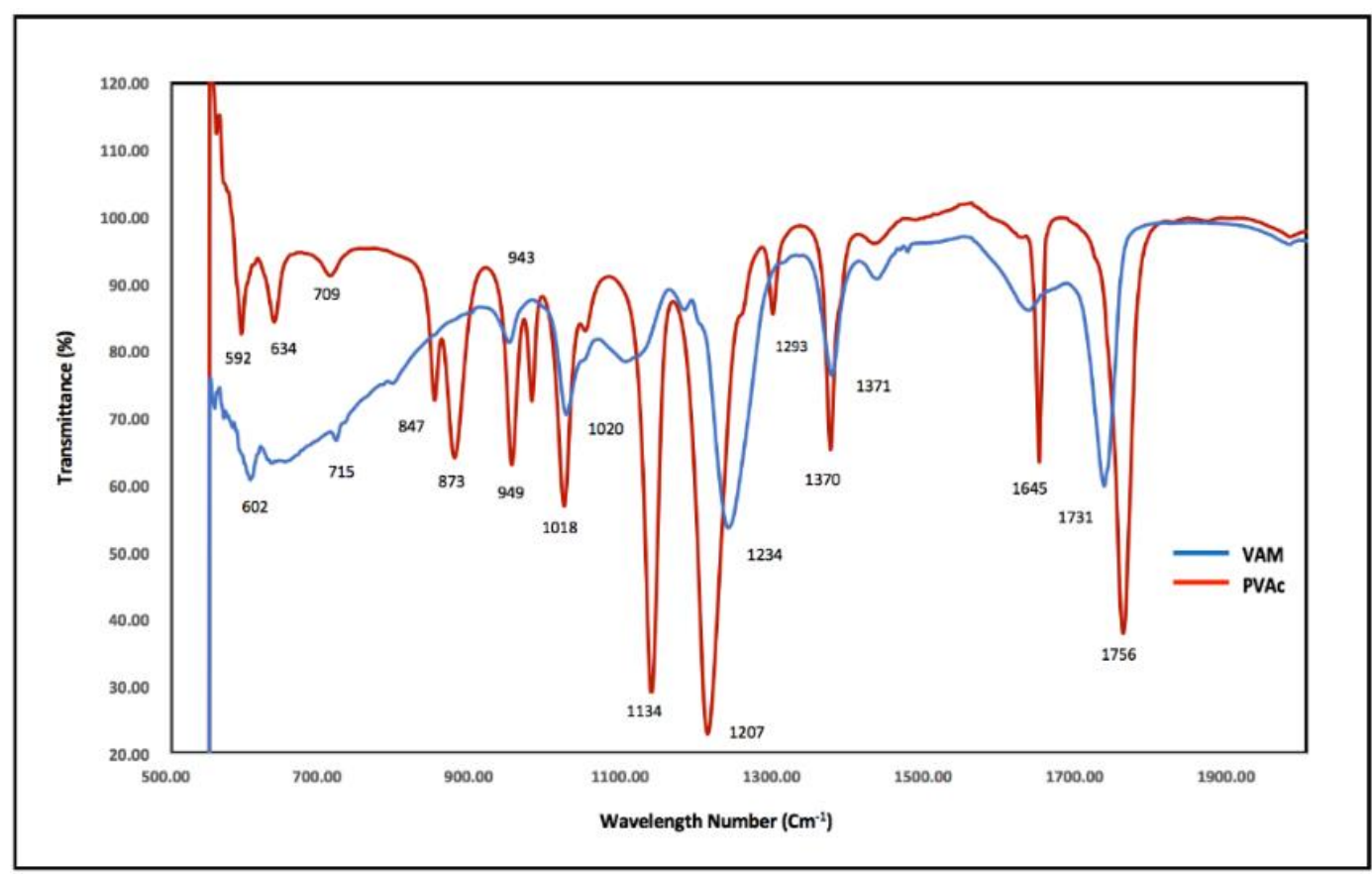

FIGURE 3. Characterization functional group of PVAc Emulsion vs VAM using FTIR 


\section{CONCLUSION}

The synthesized Polyvinyl Acetate emulsion used Vinyl acetate monomer (VAM) through emulsion polymerization technique by the presence of $3 \%$ surfactant, and the protective colloid solution obtained a different result. The improvement method is to define successful looks from the monomer conversion increase when the presence of surfactant and protective colloid is added. On the other hand, the absence of both additional compounds decreased the monomer conversion. The polymerization condition was carried out is able to produce PVAc emulsion indicated by FTIR Spectrophotometer which specific at wavelength 3310$3444 \mathrm{~cm}^{-1}, 2935 \mathrm{~cm}^{-1}, 1756 \mathrm{~cm}^{-1}, 1370 \mathrm{~cm}^{-1}, 1207-1018 \mathrm{~cm}^{-1}$ with the highest monomer conversion is $8.20 \%$.

\section{ACKNOWLEDGMENT}

The authors gratefully acknowledge the support of the Postgraduate Program of Materials Science Universitas Indonesia for the research facilities. We are thankful for the financial support provided by the Directorate of Research and Development Universitas Indonesia under program Grants of International Publication Indexed (PUTI) Proceeding under contract number NKB-1018/UN2.RST/HKP.05.00/2020.

\section{REFERENCES}

[1] C. Liza and N. S. Wahyuni, "Sentra Polimer," Media Informasi Polimer, Sentra Teknologi Polimer, tahun VII nomor 30 - ed Agustus 2019, ISSN-1693-6132, 2009.

[2] D. Braun et al., "Polymer Synthesis," Theory and Practice, Fundamentals, Methods, Experiment, Berlin Heidelberg: Springer, 2005, vol. 7, pp. 385.

[3] A. P. Rochmadi, "Mengenal Polimer dan Polimerasisasi," UGM PRESS: Yogyakarta, 2018.

[4] I. S. D. Buruanga et al., "Nonlinear control of maximum production rate of latexes of well-defined composition," Ind. Eng. Chem. Chem. Eng., Data Ser, 1997, pp. 42434254 .

[5] A. A. Herrera et al., "Dynamic optimization and experimental validation of a pilot scale emulsion polymerization reactor," Chemical Engineering and Processing - Process Intensification, vol. 144, pp. 107635, June. 2019.

[6] A. Gharieh, S. Khoee, and A. R. Mahdavian, "Emulsion and miniemulsion techniques in preparation of polymer nanoparticles with versatile characteristics," Advances in Colloid and Interface Science, vol. 269, pp. 152-186, 2019.

[7] N. Jain, V. K. Singh, and S. Chauhan, "A review on mechanical and water absorption properties of polyvinyl alcohol based composites/films." Journal of the Mechanical Behavior of Materials, vol. 26, no. 5-6, pp. 213-222, 2017.

[8] M. T. Celis et al., "Role of emulsifier on the particle size and polymer particle size distribution using multiwavelength spectroscopy measurements," Journal of Dispersion Science and Technology, vol. 38, no. 11, pp. 1600-1606, 2017.

[9] U. Khromiak et al., "Synthesis and properties of adhesive polymer-methylmethacrylate materials," International Journal of Polymer Science, 2018. 
[10] Y. Javadzadeh and S. Hamedeyazdan (April 3rd 2014). Floating Drug Delivery Systems for Eradication of Helicobacter pylori in Treatment of Peptic Ulcer Disease, Trends in Helicobacter pylori Infection, Bruna Maria Roesler, IntechOpen [Online]. Available: https://doi.org/http://dx.doi.org/10.5772/57353.

[11] H. Li, et al., "Novel ionic liquid-type Gemini surfactants: Synthesis, surface property and antimicrobial activity," Colloids and Surfaces A: Physicochemical and Engineering Aspects, vol. 395, pp. 116-124, 2012.

[12] S. Copelliet et al., "Emulsion polymerization of vinyl acetate: Safe optimization of a hazardous complex process," Journal of Hazardous Materials, vol. 192, no. 1, pp. 8-17, 2011.

[13] H. Berber, Y. Tamer, and H. Yildirim, "The effects of feeding ratio on final properties of vinyl acetate-based latexes via semi-continuous emulsion copolymerization," Colloid and Polymer Science, vol. 296, no. 1, pp. 211-221, 2018.

[14] M. I. J. Hanafi, "Effect of Montmorillonite Addition on The Thermal Resistance Properties of Polyvinyl Acetate," Jurnal Sains dan Seni ITS, vol. 5, no. 1, pp. C31-C36, 2016.

[15] J. C. Cazotti et al., "Effect of clay type on the properties of hybrid latexes of poly(vinyl acetate) and montmorillonite prepared via surfactant-free emulsion polymerization," Polymer Bulletin, vol. 76, no. 12, pp. 6305-6325, 2019.

[16] K. Nakabayashi and H. Mori, "Recent progress in controlled radical polymerization of N-vinyl monomers," European Polymer Journal, vol. 49, no. 10, pp. 2808-2838, 2013.

[17] C. S. Chern, "Principle and Application Emulsion Polymerization," New Jersey: John Willey and Sons, 2008.

[18] W. B. Chu et al., "The effects of $\mathrm{pH}$, molecular weight and degree of hydrolysis of poly(vinyl alcohol) on slot die coating of PVA suspensions of TiO2 and SiO2," Colloids and Surfaces A: Physicochemical and Engineering Aspects, vol. 302, pp. 1-10, 2007.

[19] J. M. Asua, "Emulsion Polymerization: From Fundamental Mechanisms to Process Developments," Journal of Polymer Science, Part A: Polymer Chemistry, vol. 42, no. 5, pp. 1025-1041, 2004.

[20] M. Fitri and L. Atmaja, "Polimerisasi Emulsi Polivinil Alkohol dan Monomer Vinil Asetat dalam Campuran Pelarut Etil Asetat-Air pada Sintesis Polivinil Asetat," Jurnal Sains dan Seni Pomits, vol. 2, no. 1, pp. 1-5, 2014. 